\title{
Coupling Proteomics and Fermentation Technology for the Improvement of Bioactive Molecule Production Yield in Actinomycetes
}

\section{Giuseppe Gallo*}

Department of Biological, Chemical and Pharmaceutical Sciences and Technologies, University of Palermo, Italy

Most bioactive molecules (like anticancers, antitumors, antibiotics, immunosuppressants, insecticidals, antivirals, herbicidals, antifungals) with valuable industrial and market value are naturally produced by actinomycetes [1-4], Gram-positive filamentous bacteria widespread in both terrestrial and aquatic environments [5,6]. Out of thousands of bioactive molecules, also known as secondary metabolites since they are not essential for actinomycete growth in standard laboratory condition at least, more than $50 \%$ are synthesised by strains of Streptomyces genus [4]. Despite the cellular and ecological role of secondary metabolites is still debated [3,7], microbial fermentation is widely exploited to produce these compounds at industrial level. Although they have many different activities and range within a vast chemical complexity and diversity, there are two main common issues which could be addressed for the establishment of a cost-effective microbial fermentation process:

1) bioactive production is strictly coordinated with a complex physiological differentiation program, as it has been extensively demonstrated in Streptomyces coelicolor, the model strain of this group of bacteria $[8,9]$.

2) under typical laboratory conditions bioactive molecule yield is usually low-level or null at all in some cases.

Thus, the development of a robust and economically feasible production process for secondary metabolites implies the study of strain physiology combined with a detailed knowledge of the production process and its scalability to industrial level. Anyhow, each actinomycete species requires its own optimised fermentation conditions to obtain high production titre of any specific secondary metabolite. Therefore, there are few general strategies and basic guidelines which could lead to yield improvement. At the industrial level most efforts for the development of an efficient fermentation process have been principally done in medium composition optimization by using time-consuming empirical trials. Effective computational and statistical approaches were recently used as predictive methods which could replace traditional one-factor-at-a-time technique used for optimizing actinomycete growth conditions [10,11]. Anyhow, these approaches could take further advantages from a more comprehensive understanding of strain physiology. On the other hand, generations of high yielding strains through, i) combination of random chemical mutagenesis and recombination [12-14], ii) expression of secondary metabolite genes in heterologous hosts $[15,16]$ and iii) spontaneous mutations and antibiotic resistance selection [17-19] are well documented too. However, with the advent of "omics" technologies a change in strategy happens, since the chance of managing huge amount of molecular insights on strain physiology, gene expression and biochemical capabilities introduced new perspectives as never before [20].

In particular, although proteomics is characterized by expensive and multi-step labour-intensive techniques it is actually the most powerful "omics" tool (Table 1), since it can give answers to more than one biological question [21,22], such as: gene expression (which and how much gene product is present and presumably works); protein regulation and turn-over (covalent modification occurrence and degradation); interacting partners (multi protein complexes); topological distribution (cytoplasm, membrane localization). Besides that, the functional clusterization of proteins (according to metabolic pathway databases) can give a clear picture of which biochemical pathways and cellular processes happen or are necessary as cellular response during a particular condition, growth stage or perturbation. In other words, proteomics can give an account of which molecular strategy can be performed by organisms, cells or tissues during a specific physiological need. Thus the study at the proteome level of changes occurring in actinomycetes between unproductive growth stages (or growth conditions) and those in which secondary metabolism production is switched on can reveal [23-25]: molecular event(s) or metabolic signal(s) triggering or stopping bioactive molecule production; relationships between primary metabolite supply and bioactive molecule biosynthesis; hierarchical cascade of regulatory effectors controlling secondary metabolism biosynthetic genes (including resistance mechanisms in the case of antibiotic production). Knowledge gained from proteomics can be then used as background to drive rational approaches for growth condition modifications (i. e. changes in medium composition, oxygen supply and $\mathrm{pH}$ ) and/or strain improvement (engineering of targeted regulatory, metabolic, stress response and biosynthetic genes)

Due to the vast range of scientific aspects that could arise especially when working on rare actinomycetes, a multidisciplinary approach is often required to have good chances of success in getting significant results in terms of improved production at the industrial level. The establishment of "omics" (genome sequencing is necessary and metabolomics is complimentary to proteomics) and also classical molecular genetic tools (i.e. transformation protocols), cultivation protocols (mycelium storage, growth parameters, medium recipes), endproduct recovery and process scaling-up are all examples of the variety and complexity of matters that have to be managed and integrated. Thus, scientific consortia, made by companies, like Small or Medium Enterprise (SME) and academic research laboratories, can successfully address many of these scientific problems. As an example, the LAPTOP scientific project (http://www.jic.ac.uk/laptop/), financed by EU from July 2010 to June 2013, combined the experiences and expertises from SMEs and academy research laboratories with the aim to develop a production process for the lantibiotic NAI-107, a new promising antibiotic with the potential to treat life-threatening infections caused

*Corresponding author: Giuseppe Gallo, Department of Biological, Chemical and Pharmaceutical Sciences and Technologies,University of Palermo, Italy. Tel: +39 091 23897312; E-mail: giuseppe.gallo@unipa.it

Received December 07, 2013; Accepted December 09, 2013; Published December 17, 2013

Citation: Gallo (2013) Coupling Proteomics and Fermentation Technology fo the Improvement of Bioactive Molecule Production Yield in Actinomycetes. Ferment Technol 2: e118. doi:10.4172/2167-7972.1000e118

Copyright: (c) 2013 Gallo. This is an open-access article distributed under the terms of the Creative Commons Attribution License, which permits unrestricted use, distribution, and reproduction in any medium, provided the original author and source are credited. 
Citation: Gallo (2013) Coupling Proteomics and Fermentation Technology for the Improvement of Bioactive Molecule Production Yield in Actinomycetes. Ferment Technol 2: e118. doi:10.4172/2167-7972.1000e118

Page 2 of 2

\begin{tabular}{|c|c|c|}
\hline "omics" tool & Advantages & Disadvantages \\
\hline Genomics & $\begin{array}{c}\text { Qualitative. Relatively cheap; in silico predictive models may be generated } \\
\text { concerning strain biochemistry and metabolic pathways. }\end{array}$ & No information about gene expression and regulation thereof. \\
\hline Transcriptomics & $\begin{array}{c}\text { Quantitative and qualitative. Relatively cheap. Number of genes to be } \\
\text { analysed may include all the predicted ORFs or just a restricted number } \\
\text { of them. }\end{array}$ & $\begin{array}{c}\text { Genome sequence must be available. Abundance levels may be } \\
\text { misinterpreted due to post-transcriptional regulatory events. }\end{array}$ \\
\hline Proteomics & $\begin{array}{c}\text { Quantitative and qualitative information. Analysis of post-translational } \\
\text { regulatory event(s). Topological distribution insights. Interaction study. }\end{array}$ & $\begin{array}{c}\text { Genome sequence must be available. Labour-intensive. Expensive. } \\
\text { Not the } \\
\text { optimization of procedures are often required. }\end{array}$ \\
\hline Metabolomics & Quantitative and qualitative information. Detection of end-products of \\
cellular processes. & $\begin{array}{c}\text { Labour-intensive. Expensive. Not the whole metabolite complement } \\
\text { can be analysed. }\end{array}$ \\
\hline
\end{tabular}

Table 1: Comparison between different "omics".

by multi-drug resistant Gram-positive pathogens [26,27]. NAI-107 is produced by fermentation of the actinomycete Microbispora sp. Since no lantibiotics are industrially produced as drugs for human use and there are no examples of industrial use of Microbispora genus, delivering a high quantity of high quality compound is extremely challenging. By means of proteomics many basic physiological aspects of Microbispora sp. growth and NAI-107 production were elucidated and, in just three years, this collaborative project produced enough knowledge and genetic tools that can lead to an efficient production process by generating and utilizing high producing strains, improved production media coupled with an efficient recovery process.

Thus, such similar combined and cooperative strategies may become standard models for industrial development based on modern molecular genetic tools and classical actinomycete fermentation techniques.

\section{References}

1. Demain AL (1999) Pharmaceutically active secondary metabolites of microorganisms. Appl Microbiol Biotechnol 52: 455-463.

2. Donadio S, Maffioli S, Monciardini P, SosioM, Jabes D (2010) Antibiotic discovery in the twenty-first century: current trends and future perspectives. $J$ Antibiot (Tokyo) 63:423-30.

3. Demain, AL, Fang A (2000) The natural functions of secondary metabolites Advances in biochemicalengineering/biotechnology 69: 1-39.

4. Chaudhary AK, Dhakal D,Sohng JK (2013) An Insight into the "-Omics" Based Engineering of Streptomycetes for Secondary Metabolite Overproduction. BioMed Research International 2013.

5. Hopwood DA (2007) Therapeutic treasures from the deep.Nature Chemical Biology3: 457 - 458.

6. Servin JA, Herbold CW, Skophammer RG, Lake JA (2007) Evidence excluding the root of the tree of life from the actinobacteria. MolBiolEvol 25: 1-4.

7. Davies J. Are antibiotics naturally antibiotics? J IndMicrobio/Biotechnol 33: 496499.

8. Bibb MJ (2005) Regulation of secondary metabolism in Streptomycetes. CurrOpinMicrobiol 8: 208-215.

9. Manteca A, Alvarez R, Salazar N,Yague P, Sanchez J (2008) Mycelium differentiation and antibiotic production in submerged cultures of Streptomyces coelicolor. Appl Environ Microbiol 74.

10. Adinarayana K, Ellaiah P, Srinivasulu B, Bhavani DR, Adinarayana G (2003) Response surface methodological approach to optimize the nutritional parameters for neomycin production by Streptomyces marinensisunder solidstate fermentation. Process Biochem 38: 3877-3886.

11. da Silva IR, Martins MK, Carvalho CM, de Azevedo JL, de Lima Procópio RE (2012) The effect of varying culture conditions on the production of antibiotics by Streptomyces spp., isolated from the Amazonian soil. Ferment Technol.

12. Baltz RH (1986) Mutagenesis in Streptomyces. In: Demain AL, Soloman NA (Eds) Manual of industrial microbiology and biotechnology. American Society for Microbiology.
13. Matsushima P, Baltz RH (1986) Protoplast fusion.In: Demain AL, Soloman NA (Eds) Manual of industrial microbiology and biotechnology. American Society for Microbiology.

14. Chen X, Wei P, Fan L, Yang D, Zhu X, et al. (2009) Generation of high-yield rapamycin-producing strains through protoplasts-related techniques. Appl Microbiol Biotechnol 83: 507-512.

15. Baltz RH (2001) Genetic methods and strategies for secondary metabolite yield improvement in actinomycetes. Antonie van Leeuwenhoek 79: 251-259.

16. Alduina R, Gallo G (2012) Artificial chromosomes to explore and to exploit biosynthetic capabilities of actinomycetes. Journal of Biomedicine and Biotechnology 2012

17. Hu H, Zhang Q, Ochi K (2002) Activation of antibioticbiosynthesis by specified mutations in the rpoB gene (encoding the RNA polymerase $\beta$ subunit) of Streptomyces lividans. J Bacteriol 184: 3984-3991.

18. Xu J, Tozawa Y, Lai C, Hayashi H, Ochi K (2002) A rifampicin resistance mutation in the rpoB gene confers ppGpp-independent antibiotic production in Streptomyces coelicolor A3(2). Mol Gen Genet 268:179-189.

19. $\mathrm{Hu} \mathrm{H}$, Ochi K (2001) Novel approach for improving the productivity of antibioticproducing strains by inducing combined resistance mutations. Appl Environ Microbiol 67:1885-1892.

20. Baltz RH (2011) Strain improvement in actinomycetes in the postgenomic era. J IndMicrobiolBiotechno/38:657-66.

21. Tabandeh F, Shariati P Khodabandeh M (2012) Application of TwoDimensional Gel Electrophoresis to Microbial Systems. In: Magdeldin S (ed) Gel Electrophoresis - Principles and Basics.

22. Otto A, Bernhardt J, Hecker M, Becher D (2012) Global relative and absolute quantitation in microbial proteomics. Curr Opin Microbio/15: 364-372.

23. Alduina R, Gallo G, RenzoneG, Weber T, Scaloni A, et al. (2013) Novel Amycolatopsisbalhimycina biochemical abilities unveiled by proteomics. FEMS Microbiol Lett PubMed PMID: 24246022.

24. Gallo G, Alduina R, Renzone G, Thykaer J, Bianco L, et al. (2010) Differentia proteomic analysis highlights metabolic strategies associated with balhimycin production in Amycolatopsis balhimycina chemostat cultivations. Microb Cell Fact 26.

25. Gallo G, Renzone G, Alduina R, Stegmann E, Weber T, et al. (2010) Differentia proteomic analysis reveals novel links between primary metabolism and antibiotic production in Amycolatopsis balhimycina. Proteomics10: 1336-1358.

26. Vasile F, Potenza D, Marsiglia B, Maffioli S, Donadio S (2012) Solution structure by nuclear magnetic resonance of the two lantibiotics 97518 and NAl-107. J Pept Sci 18:129-134

27. Jabés D, Brunati C, Candiani G, Riva S, Romanó G, et al. (2011) Efficacy of the new lantibiotic NAl-107 in experimental infections induced by multidrugresistant Gram-positive pathogens. Antimicrob Agents Chemother 55:1671 1676

Citation: Gallo (2013) Coupling Proteomics and Fermentation Technology fo the Improvement of Bioactive Molecule Production Yield in Actinomycetes. Ferment Technol 2: e118. doi:10.4172/2167-7972.1000e118 